\title{
ARTICLES
}

\section{Fas Gene Mutations in Prostatic Intraepithelial Neoplasia and Concurrent Carcinoma: Analysis of Laser Capture Microdissected Specimens}

\author{
Hitoshi Takayama, Tetsuya Takakuwa, Zhiming Dong, Norio Nonomura, \\ Akihiko Okuyama, Shigekazu Nagata, and Katsuyuki Aozasa
}

Departments of Pathology (HT, TT, ZD, KA), Urology (NN, AO), and Genetics (SN), Osaka University Medical School, Osaka, Japan

SUMMARY: Fas (Apo-1/CD95) is a cell-surface receptor involved in cell death signaling through binding of Fas ligand. Mutations of the Fas gene might be involved in proliferative diseases of the prostate by prolongation of programmed cell death of prostatic epithelial cells. Using the laser capture microdissection method, Fas gene mutations were examined on genomic DNA extracted from lesions with high-grade prostatic intraepithelial neoplasia (HGPIN), a possible precursor of prostatic cancer (PCA), and from PCA. A total of 193 lesions, 111 with HGPIN, 55 with PCA, and 27 benign glands, were microdissected from 27 patients with PCA. Polymerase chain reaction-amplified products were directly sequenced. Loss of heterozygosity (LOH) was examined at four sites of known polymorphisms. Fas gene mutations were detected in HGPIN: 4 of 27 (14.8\%) cases or 4 of 111 (3.6\%) lesions. All were point mutations: three missense and one nonsense in the death domain. Benign proliferative glands adjoining HGPIN and/or PCA, and PCA never showed mutations. LOH was found in $31.3 \%$ of PCA and $25 \%$ of HGPIN lesions, but was never found in benign glands. Exclusive occurrence of Fas mutations in HGPIN might underlie the development of these lesions. Occasional findings of LOH in HGPIN and PCA suggested that genetic instability might occur during the early phase of prostatic carcinogenesis. (Lab Invest 2001, 81:283-288).

\begin{abstract}
D rostatic intraepithelial neoplasia (PIN) is charac1 terized by intraluminar proliferation of epithelial cells in ducts and acini. PIN frequently coexists with prostatic carcinoma (PCA) (Bostwick, 1995; Bostwick and Brawer, 1987; Skjørten et al, 1997) and is commonly found in the nontransition zone, which is the predominant site for PCA (de la Torre et al, 1993; Qian et al, 1997). According to histologic and cytologic findings, PIN is divided into high-grade PIN (HGPIN) and low-grade PIN (LGPIN) (Montironi et al, 1996). Previous histopathologic study of whole-mount prostatectomy specimens showed the proximity of HGPIN lesions but not LGPIN lesions to PCA (Shin et al, 2000). Recent studies revealed that HGPIN and PCA share common cytogenetic features. Allelic loss of chromosome $8 p$ is frequent in both HGPIN and invasive PCA (Emmert-Buck et al, 1995; Häggman et al, 1997). Mutations of the $H$-ras gene were closely associated with progression of HGPIN into invasive PCA in transgenic mice, although this was not confirmed in humans (Shibata et al, 1996). These findings indicated
\end{abstract}

Received June 21, 2000.

Address reprint requests to: Dr. Katsuyuki Aozasa, Department of Pathology (C3), Osaka University Medical School, Yamada-oka 2-2, Suita, Osaka 565-0871, Japan.E-mail: aozasa@molpath.med.osaka-u.ac.jp that HGPIN but not LGPIN is the most likely precursor lesion for PCA.

HGPIN lesions could be defined only at the microscopic level and therefore immunohistochemical procedures have been the main modalities used to analyze its biologic characteristics. Crowded cells in the HGPIN lesions were occasionally labeled with an antibody (MIB-1) against proliferating cells (Häussler et al, 1999). Meanwhile, foci of HGPIN were strongly immunoreactive with Bcl-2 (Häussler et al, 1999; Stattin et al, 1996), suggesting that programmed cell death (apoptosis) is prolonged in HGPIN.

Fas antigen is a $45-\mathrm{kDa}$ transmembrane protein of the TNF receptor superfamily that can induce programmed cell death (apoptosis) through cross-linkage with Fas ligand (FasL) (Nagata, 1997; Suda et al, 1993). Fas is located on chromosome 10q24.1 and is comprised of 9 exons and 8 introns. The Fas extracellular domain contains three cysteine-rich motif repeats encoded by exons 2 to 5 . Its transmembrane domain consists of the last $49 \mathrm{bp}$ of exon 6 and the first $2 \mathrm{bp}$ of exon 7 . The remaining $81 \mathrm{bp}$ in exon 7 , the $25 \mathrm{bp}$ in exon 8 , and 329 bp in exon 9 comprise the cytoplasmic region (Cheng et al, 1995). Fas is expressed in a wide range of tissues including the thymus, liver, and activated T and B lymphocytes (Itoh et al, 1991; 
Watanabe-Fukunaga et al, 1992). A mutation in the death domain of the Fas gene leads to loss of its apoptosis function, a loss-of-function mutation, which might contribute to the pathogenesis of human malignancies. Indeed Fas gene mutations have been reported in both the lymphoid lineage and epithelial malignancies: approximately $10 \%$ of cases with multiple myeloma (Landowski et al, 1997) and sporadic non-Hodgkin's lymphoma (Grønbæck et al, 1998), $7.7 \%$ in lung cancer (Lee et al, 1999a), and 28\% in urinary bladder cancer (Lee et al, 1999b).

Laser capture microdissection under direct microscopic visualization enables rapid one-step procurement of selected human cell populations from histologic sections. This method facilitates microdissection of selected cells, and thus extensive studies of the objective lesions are now possible. Using this method on whole-mount samples, we selectively microdissected numerous PIN and PCA lesions from 27 patients with PCA. Genomic DNA extracted from each lesion was analyzed for Fas mutations.

\section{Results}

\section{Fas Gene Mutations}

As shown in Table 1, four mutations of the Fas gene were detected in four HGPIN lesions from four cases. There were no prominent differences in frequency of mutations or loss of heterozygosity (LOH) in HGPIN or PCA lesions between noncastrated and castrated cases. All mutations were point mutations: three missense and one nonsense mutation detected in exon 9, which encodes the death domain region of the Fas receptor (Nagata, 1997). Substitutions at codon 260 of the Fas cDNA sequence (Gene Bank accession No. M67454), Gln to Stop (Case 10) and Gln to Arg (Case 21), respectively, were found in the HGPIN lesions. All of the mutations were transitions: $C$ to $T$ and $A$ to $G$. No $G$ to $C$ or $C$ to $A$ transversions were found. All of the HGPIN lesions with mutations were present in the nontransition zone. Neither PCA nor benign proliferative glands adjoining HGPIN and/or PCA showed Fas mutations.

\section{Allelic Status}

Sixteen of 27 (59.6\%) cases were heterozygous for one or more sites of the known biallelic polymorphisms, ie, at positions -1377, -670, 416, and 836 . Of these 16 cases, 5 (31.3\%) with PCA and 4 (25\%) with HGPIN showed $\mathrm{LOH}$ in the promoter region $(-670)$ or exon 7 . The HGPIN lesion in Case 24 had a missense mutation at position 1099 and LOH at -670 . In Case 21, the HGPIN lesion had a mutation at exon 9 but no $\mathrm{LOH}$, and the PCA lesion had $\mathrm{LOH}$ but no mutation.

\section{Immunohistochemistry}

Results of immunohistochemical study in lesions with Fas gene mutations and $\mathrm{LOH}$ are summarized in Table 1. Fas protein was expressed in 11 of 15 (73.3\%)
HGPIN lesions and 5 of 6 PCA (83.3\%) lesions. No relationship was found between immunoreactivity for anti-Fas antibody and mutation or LOH in HGPIN and PCA lesions.

\section{Discussion}

Information regarding the molecular genetic characteristics of PIN was quite limited until development of the microdissection technique. Previous studies showed that allelic loss of chromosomes 8p, 10q, and $16 q$ was frequent in both HGPIN and invasive PCA, suggesting the involvement of tumor suppressor genes or oncogenes at these loci (Emmert-Buck et al, 1995; Gray et al, 1995; Häggman et al, 1997; Strup et al, 1999). Through construction of a detailed deletion map spanning 10q23-25, Gray et al (1995) suggested the presence of prostate tumor suppressor genes near the 10q23-24 boundary, which is close to the location of the Fas gene, 10q24.1. Using the laser capture microdissection method, we analyzed the Fas gene mutations in numerous HGPIN lesions; Fas gene mutations were detected in 4 of $27(14.8 \%)$ cases or 4 of 111 (3.6\%) lesions with HGPIN. In contrast, none of 55 lesions with PCA had Fas gene mutations, indicating that PCA develops in HGPIN without Fas gene mutations. Fas gene mutations were never detected in benign proliferative glands adjoining HGPIN and/or PCA. Taken together, these observations suggest that Fas gene mutation might not contribute to the pathogenesis of PCA, in contrast to lung cancer, hematologic malignancies, and bladder cancer (Lee et al, 1999a, 1999b).

With regard to the sites and patterns of mutations in the Fas gene, a point mutation at codon 253 was reported in two patients with multiple myeloma (Landowski et al, 1997). In non-Hodgkin's lymphomas, mutations at codons 248 and 251 were identified (Grønbæck et al, 1998). Lee et al (1999b) reported that 8 of 12 mutations found in bladder cancer showed a G to $A$ transition at codon 251 , suggesting that this might be a mutational hotspot. Two of the current HGPIN lesions showed mutations at codon 260. All of the mutations in the current series were transitions, suggesting that some "endogenous" mutagens act in the pathogenesis of HGPIN.

Missense mutations in the death domain have been suggested to affect receptor function in a dominantnegative fashion (Fisher et al, 1995), ie, mutant Fas protein derived from one mutated Fas allele might bind with normal Fas protein derived from the other normal allele to construct a structurally abnormal Fas trimer, which might have a defect in binding to adapter proteins. Among four HGPIN lesions with Fas gene mutations, one informative case (Case 24) had LOH at position -670 . As the distance between the site of $\mathrm{LOH}$ and the mutation was approximately $10 \mathrm{~kb}, \mathrm{LOH}$ might involve the mutation site in the same allele. Therefore, it is reasonable to consider that the $\mathrm{LOH}$ and mutation found in the HGPIN lesion in Case 24 occurred in different alleles, thus resulting predominantly in production of mutant Fas protein. The occur- 


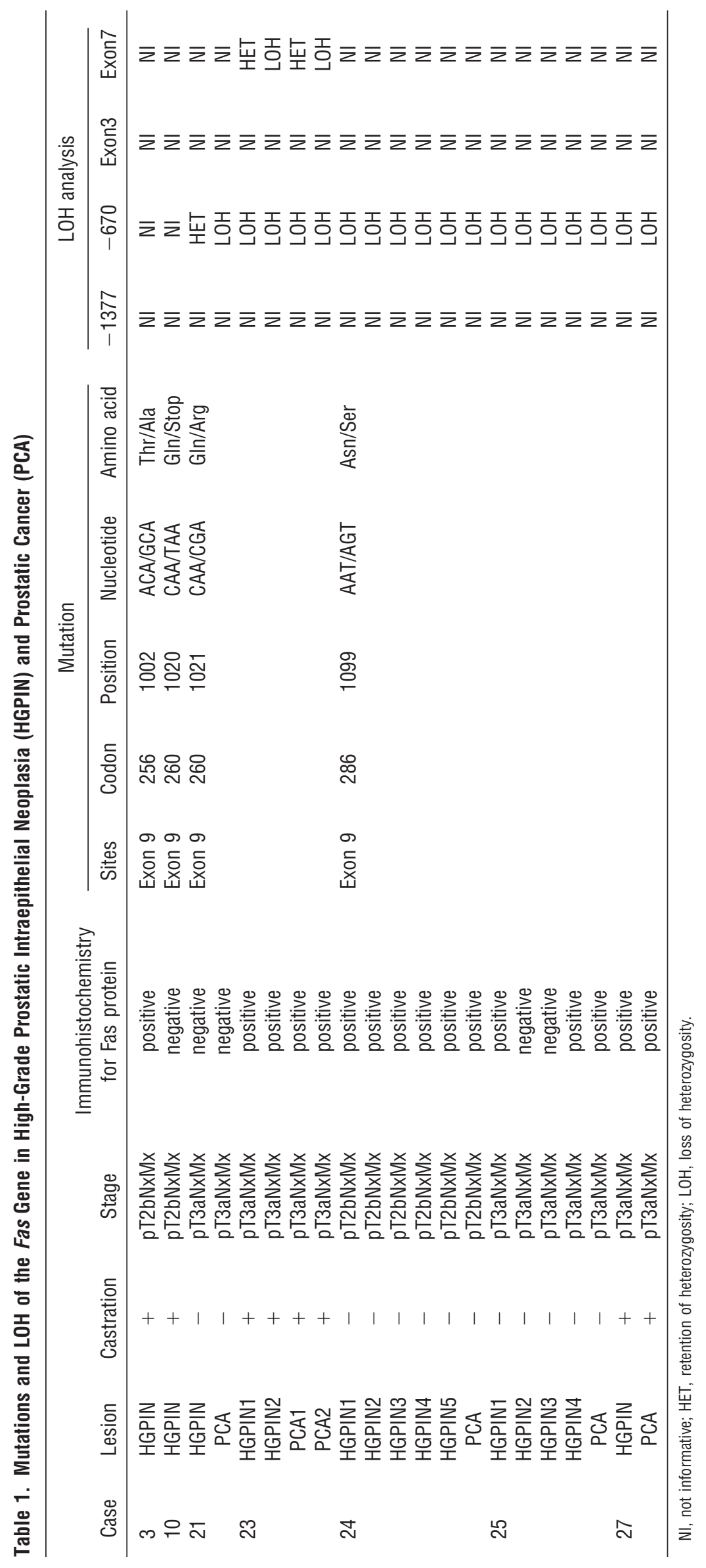


rence of $\mathrm{LOH}$ was unknown in the remaining three cases (Case 3, 10, 21) with Fas mutations. Fas function might have been lost or reduced due to a dominant-negative effect of mutant Fas protein in cases without LOH or because of predominant production of mutant Fas protein in cases with $\mathrm{LOH}$. Fas-mediated apoptosis was suggested to be disrupted in these four HGPIN lesions.

The normal DNA repair mechanism is important for maintaining the integrity of the genome. Humans are frequently exposed to naturally occurring DNAdamaging agents, and the combined occurrence of DNA damage and impaired DNA repair function results in development of neoplasia. Indeed, replication errors, as revealed by microsatellite instability (MSI), were reported in cases with PCA (Dahiya et al, 1997; Rohrbach et al, 1999). The occurrence of $\mathrm{LOH}$ also indicates the underlying genetic instability in lesional proliferating cells. Rohrbach et al (1999) reported that $\mathrm{MSI}$ and $\mathrm{LOH}$ were found in $35 \%$ and $16 \%$, respectively, of their PCA cases. In the present study, LOH at four sites in the Fas gene was found in $31.6 \%$ of PCA and $25 \%$ of HGPIN lesions. LOH of the Fas gene was never found in the benign lesions. Previous studies suggested that HGPIN is the precursor lesion of PCA (Bostwick, 1995; Bostwick and Brawer, 1987; Skjørten
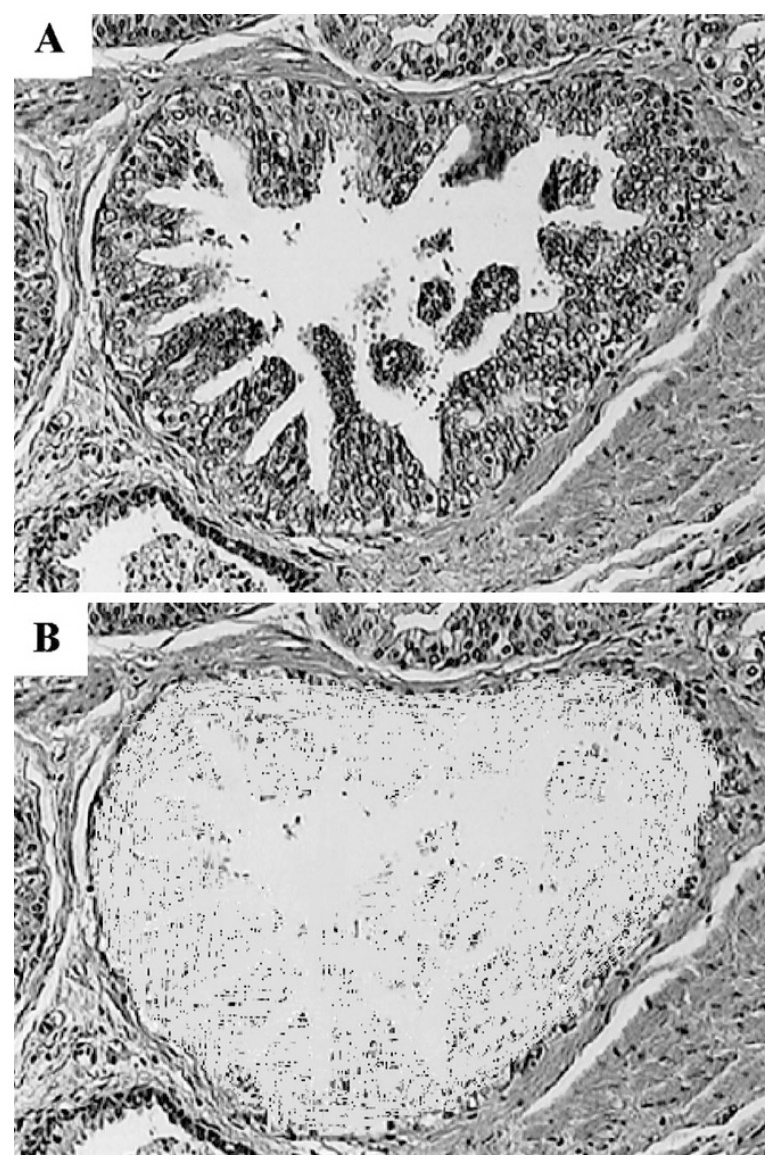

Figure 1.

High-grade prostatic intraepithelial neoplasia (HGPIN) lesion (A) in a representative case was successfully microdissected (B). Note successful resection of intraductal epithelial cells. Hematoxylin and eosin staining; original magnification, $\times 200$.

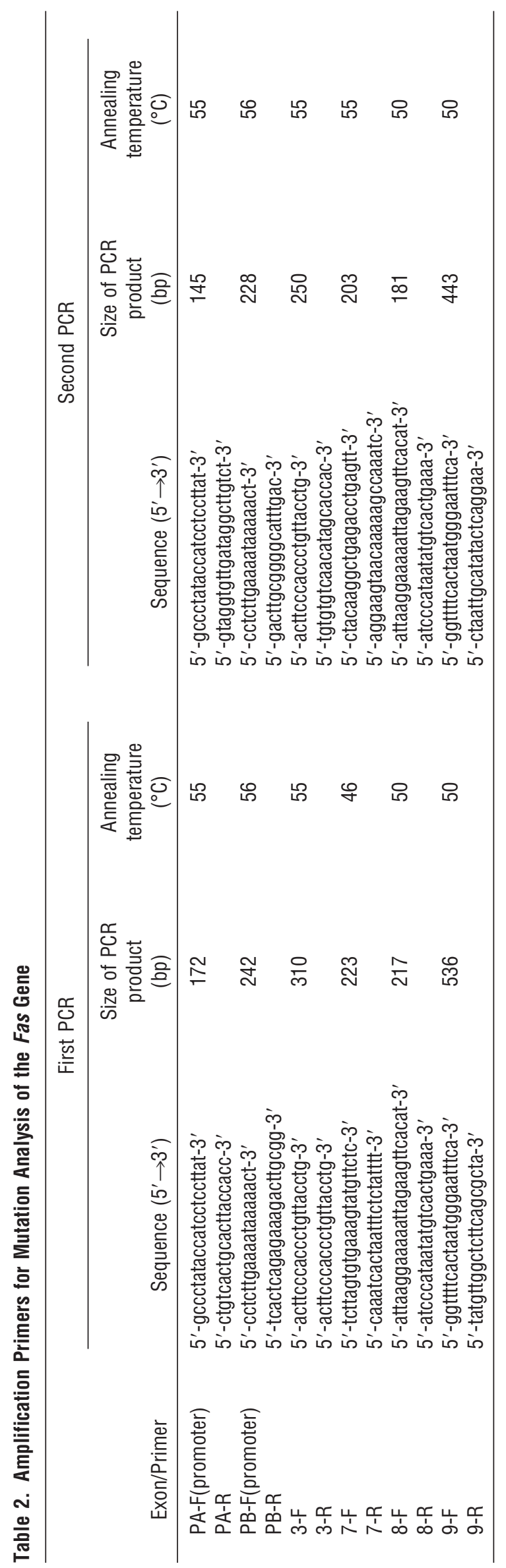


et al, 1997), and the present results showed that genetic instability occurred during the early phase of prostatic carcinogenesis.

In conclusion, Fas gene mutations were exclusively found in the HGPIN lesions, which might underlie the development of these lesions.

\section{Materials and Methods}

\section{Patients}

Twenty-seven patients, who had received total prostatectomy under the diagnosis of PCA, were selected for the present study. All of the patients were admitted to our hospitals between 1996 and 1998. Fourteen patients received androgen deprivation therapy (castration): $\mathrm{LH}-\mathrm{RH}$ agonist (leuprolide) for 2 to 6 months (mean 3.4 months) together with the antiandrogen agents (flutamide or chlormadinone). The remaining 13 patients did not receive this treatment (noncastrated). The present cases were conventionally subdivided into the preoperatively noncastrated group (13 cases) and medically castrated group (14 cases). None of the 27 patients received preoperative chemotherapy or radiation therapy.

Histologic findings in a subpopulation of these cases were reported previously (Shin et al, 2000). Based on the American staging system (modified by Whitmore-Jewett) (Bostwick et al, 1994), pathologic stage was determined as follows: 11 (41\%) cases were in stage T2 and 16 (59\%) were in stage T3. Histologic specimens were fixed in $10 \%$ neutral buffered formalin and routinely processed for paraffin embedding. Serial sections $5-\mu \mathrm{m}$ thick were cut and stained with hematoxylin and eosin, and reviewed independently by two pathologists (HT and KA). The mean number of sections examined was 9.3 per case. In problematic cases, preservation of the basal cell layer, a reliable criterion for benign prostatic lesions, was immunohistochemically examined using basal cell-specific monoclonal anti-high molecular weight cytokeratin antibody (34 $\beta$ E12; Enzo Diagnostics, New York). Diagnosis of HGPIN was made according to histologic and cytologic features; ie, intraluminal proliferation of glandular epithelial cells with large and prominent nuclei. The basal layer was partially disrupted in HGPIN.

\section{Laser Capture Microdissection and DNA Extraction}

Microdissection of each lesion was performed using a PixCell laser capture microscope (Arcturus Engineering, Santa Clara, California) according to previously described methods with some modifications (Bonner et al, 1997; Emmert-Buck et al, 1996). Briefly, histologic sections were dehydrated, and then the histologic fields of interest were selected, overlaid with thermoplastic film mounted on transparent cap, and captured on the film through laser energy (Fig. 1). The dissected pieces were allowed to adhere to the transparent cap and were collected in $0.5 \mathrm{ml}$ Eppendorf tubes. The cells were subsequently resuspended in 20 to $50 \mu$ l of extraction buffer containing $10 \mathrm{~mm}$ Tris $(\mathrm{pH}$
8.0), 2 mm EDTA, 0.2\% Tween 20, and $200 \mu \mathrm{g} / \mathrm{ml}$ proteinase $\mathrm{K}$, and incubated overnight at $37^{\circ} \mathrm{C}$. The mixture was heated at $100^{\circ} \mathrm{C}$ for 10 minutes to inactivate proteinase $\mathrm{K}$, and $3 \%$ to $5 \%$ of the solution was used as a template for each PCR. The total number of microdissected lesions from 27 cases was 193: 111 lesions from HGPIN, 55 from PCA, and 27 from benign glands.

\section{Detection of Mutations and LOH}

The death domain is necessary for transduction of the apoptotic signal (Cheng et al, 1995; Itoh and Nagata, 1993; Itoh et al, 1991). Therefore, we examined mutations in exons 7, 8, and 332 bp of exon 9. The primers used for PCR analysis are listed in Table 2. DNA was subjected to first-round PCR consisting of 10 cycles with oligonucleotide primers, followed by a second PCR consisting of 35 cycles using $0.1 \%$ of the firstround PCR products as the template, then denaturation for 30 seconds at $95^{\circ} \mathrm{C}$, annealing for $30 \mathrm{sec}-$ onds at variable temperatures, and extension for 30 seconds at $72^{\circ} \mathrm{C}$ in a 9700 Applied Biosystems Thermocycler (Foster City, California). PCR products were purified using a QIAquick PCR Purification Kit (Qiagen, Valencia, California), and were sequenced by the dideoxy chain termination method using a DNA sequencing kit (Applied Biosystems). The samples were analyzed using a Genetic Analyzer (ABI PRISM 310'; Applied Biosystems). PCR products with suspected mutations were cloned in PCR 2.1-TOPO (Invitrogen, Carlsbad, California), and sequenced to confirm the mutation.

$\mathrm{LOH}$ was examined at four sites of known polymorphisms, ie, at position $-1377,-670$ (promoter region), 416 (exon 3), and 836 (exon 7). DNA was amplified using primers flanking the four polymorphic sites (Table 1). Polymorphisms at $-1377,416$, and 836 were examined by direct sequencing, and that at position -670 by restriction fragment length polymorphism by digestion with Mva I (Fermentas, Vilnius, Lithuania) (Huang et al, 1997).

\section{Immunohistochemistry}

Immunohistochemical study of paraffin sections was carried out using the avidin-biotin peroxidase complex method. For detection of Fas protein, mouse antihuman Fas antibody (4B4-B3) that recognizes extracellular domain of Fas was prepared by Dr. S. Nagata (unpublished data). The histologic sections were deparaffinized and rinsed in three changes of PBS. Then the antibody, diluted 1:200, was applied at $37^{\circ} \mathrm{C}$ for 45 minutes. Positive cells showed an intracytoplasmic dot-like staining. Staining manner in each case was distinct, ie, almost all cells were positive in positive cases and negative in negative cases.

\section{References}

Bonner RF, Emmert-Buck M, Cole K, Pohida T, Chuaqui R, Goldstein S, and Liotta LA (1997). Laser capture microdissection: Molecular analysis of tissue. Science 278: 1481-1483. 
Bostwick DG (1995). High grade prostatic intraepithelial neoplasia: The most likely precursor of prostatic cancer. Cancer 75:1823-1836.

Bostwick DG and Brawer MK (1987). Prostatic intra-epithelial neoplasia and early invasion in prostate cancer. Cancer 59:788-794.

Bostwick DG, Myers RP, and Oesterling JE (1994). Staging of prostate cancer. Semin Surg Oncol 10:60-73.

Cheng J, Liu O, Koopman WJ, and Mountz JD (1995). Characterization of human Fas gene: Exon/intron organization and promoter region. J Immunol 154:1239-1245.

Dahiya R, Lee C, McCarville J, Hu W, Kaur G, and Deng G (1997). High frequency of genetic instability of microsatellites in human prostatic adenocarcinoma. Int J Cancer 72:762767.

de la Torre $M$, Häggman MJ, Brändstedt $S$, and Busch $C$ (1993). Prostatic intraepithelial neoplasia (PIN) and invasive carcinoma in total prostatectomy specimens: Distribution, volumes, and DNA ploidy. Br J Urol 72:207-213.

Emmert-Buck MR, Boner RF, Smith PD, Chuaqui R, Zhaung Z, Goldstein SR, Weiss RA, and Liotta LA (1996). Laser capture microdissection. Science 274:998-1001.

Emmert-Buck MR, Vocke CD, Pozzatti RO, Duray PH, Jennings SB, Florence CD, Zhuang Z, Bostwick DG, Liotta LA, and Linehan WM (1995). Allelic loss on chromosome 8p12-21 in microdissected prostatic intraepithelial neoplasia. Cancer Res 55:2959-2962.

Fisher GH, Rosenberg FJ, Straus SE, Dale JK, Middleton LA, Lin AY, Strober W, Lenardo MJ, and Puck JM (1995). Dominant interfering Fas gene mutations impair apoptosis in a human autoimmune lymphoproliferative syndrome. Cell 81:935-946.

Gray IC, Phillips SMA, Lee SL, Neoptolemos JP, Weissenbach J, and Spurr N (1995). Loss of the chromosomal region 10q23-25 in prostate cancer. Cancer Res 55:4800-4803.

Grønbæck K, Straten PT, Ralfkiaer E, Ahrenkiel V, Andersen MK, Hansen NE, Zeuthern J, Hou-Jensen K, and Guldberg P (1998). Somatic Fas mutations in non-Hodgkin's lymphoma: Association with extranodal disease and autoimmunity. Blood 92:3018-3024.

Häggman MJ, Wojno KJ, Pearsall CP, and Macoska JA (1997). Allelic loss of $8 p$ sequences in prostatic intraepithelial neoplasia and carcinoma. Urology 50:643-647.

Häussler O, Epstein JI, Amin MB, Heitz PU, and Hailemariam $S$ (1999). Cell proliferation, apoptosis, oncogene, and tumor suppressor gene status in adenosis with comparison to benign prostatic hyperplasia, prostatic intraepithelial neoplasia, and cancer. Human Pathol 30:1077-1086.

Huang QI, Morris D, and Manollos N (1997). Identification and characterization of polymorphisms in the promoter region of the human Apo-1/Fas (CD95) gene. Mol Immunol 34:577582.

Itoh N and Nagata S (1993). A novel protein domain required for apoptosis: Mutational analysis of human Fas antigen. J Biol Chem 268:10932-10937.

Itoh $\mathrm{N}$, Yonehara S, Ishii M, Yonehara S, Mizushima M, Sameshima A, Hase A, Seto $Y$, and Nagata S (1991). The polypeptide encoded by the cDNA for human cell surface antigen Fas can mediate apoptosis. Cell 66:233-243.
Landowski TH, Qu N, Buyuksal I, Painter S, and Dalton WS (1997). Mutations in the Fas antigen in patients with multiple myeloma. Blood 90:4266-4270.

Lee SH, Shin MS, Park WS, Kim SY, Kim HS, Han JY, Park GY, Dong SM, Pi JH, Kim CH, Kim SH, Lee JY, and Yoo NJ (1999a). Alterations of Fas (Apo/CD95) gene in non-small cell lung cancer. Oncogene 18:3754-3760.

Lee SH, Shin MS, Park WS, Kim SY, Kim HS, Han JY, Park GY, Dong SM, Pi JH, Kim CH, Kim SH Lee JY, and Yoo NJ (1999b). Alterations of Fas (Apo/CD95) gene in transitional cell carcinoma of urinary bladder. Cancer Res 59:30683072.

Montironi R, Bostwick DG, Bonkhoff H, Cockett ATK, Helpap B, Troncoso P, and Waters D (1996). Origins of prostate cancer. Cancer 78:362-365.

Nagata S (1997). Apoptosis by death factor. Cell 88:355-365.

Qian J, Wollan P, and Bostwick DG (1997). The extent and multi-centricity of high-grade prostatic intraepithelial neoplasia in clinically localized prostatic adenocarcinoma. Hum Pathol 28:143-148.

Rohrbach H, Hass CJ, Baretton GB, Hirschmann A, Diebold J, Behrendt RP, and Löhrs U (1999). Microsatellite instability and loss of heterozygosity in prostatic carcinomas: Comparison of primary tumors, and of corresponding recurrences after androgen-deprivation therapy and lymph-node metastases. Prostate 40:20-27.

Shibata M, Ward JM, Devor DE, Liu ML, and Green JE (1996). Progression of prostatic intraepithelial neoplasia to invasive carcinoma in C3(1)/SV40 large T antigen transgenic mice: Histopathological and molecular biological alterations. Cancer Res 56:4894-4903.

Shin M, Takayama $\mathrm{H}$, Nonomura $\mathrm{N}$, Wakatsuki A, Okuyama $A$, and Aozasa K (2000). Extent and zonal distribution of prostatic carcinoma in Japan: Analysis of whole-mounted prostatectomy specimens. Prostate 42:81-87.

Skjørten FJ, Berner A, Harvei S, Robsahm TE, and Tretli S (1997). Prostatic intraepithelial neoplasia in surgical resections. Cancer 79:1172-1179.

Stattin P, Damber JE, Karlberg L, Nordgren H, and Bergh A (1996). Bcl-2 immunoreactivity in prostate tumorigenesis in relation to prostatic intraepithelial neoplasia, grade, hormonal status, metastatic growth and survival. Urol Res 24:257-264.

Strup SE, Pozzatti RO, Florence CD, Emmert-Buck MR, Duray PH, Liotta LA, Bostwick DG, Linehan WM, and Vocke CD (1999). Chromosome 16 allelic loss analysis of a large set of microdissected prostate carcinomas. J Urol 162:590-594.

Suda T, Takahashi T, Goldstein P, and Nagata S (1993). Molecular cloning and expression of the Fas ligand, a novel member of the tumor necrosis factor family. Cell 75:11691178.

Watanabe-Fukunaga R, Brannan C, Itoh N, Yonehara S, Copeland NG, Jenkins NA, and Nagata S (1992). The cDNA structure, expression, and chromosomal assignment of the mouse Fas antigen. J Immunol 148:1274-1279. 